CrossMark <click for updates

Cite this: Phys. Chem. Chem. Phys., 2017, 19, 626

Received 27th September 2016 Accepted 23rd November 2016

DOI: $10.1039 / c 6 c p 06627 e$

www.rsc.org/pccp

\title{
Infrared dynamics study of thermally treated perfluoroimide acid proton exchange membranes
}

\author{
L. Puskar, ${ }^{\star a}$ E. Ritter, ${ }^{b}$ U. Schade, ${ }^{a}$ M. Yandrasits, ${ }^{c}$ S. J. Hamrock, ${ }^{c}$ M. Schaberg ${ }^{c}$ and \\ E. F. Aziz ${ }^{\text {ade }}$
}

\begin{abstract}
The temperature induced dehydration process of the $3 \mathrm{M}$ Brand perfluoroimide acid (PFIA), an advanced proton exchange membrane for fuel cells, was studied by in situ infrared spectroscopy to understand proton transport processes under conditions of low hydration levels. A comprehensive assignment of the vibrational bands of PFIA in the mid infrared region is provided. Investigation of the kinetics in conjunction with 2D correlation spectroscopy methods revealed the sequential process of the hydration and dehydration in a conclusive model. The results indicate that at a lower water content the sulfonate group of the PFIA side chain is preferentially ionised and involved in a hydrogen bonding structure with the sulfonyl imide acid group, until a sufficient amount of water is present to ionise the second ionic site. Comparison to the well-understood NAFION ${ }^{\mathrm{TM}}$ membrane revealed that under low humidity conditions a higher amount of water is retained in PFIA in a state most similar to liquid water. The results contribute to a better understanding of water retention capability and thus proton conductivity under high-temperature and low-humidity conditions.
\end{abstract}

\section{Introduction}

Proton exchange membranes (PEMs) play a central role in the operation of fuel cells (FCs), they separate the anode from the cathode sections and selectively allow protons to diffuse towards the cathode while blocking the oxygen and hydrogen gases. ${ }^{1}$ Perfluorinated sulfonic acids (PFSAs) have most widely been used as PEMs due to their mechanical, chemical and thermal stability, however further improvements are still in demand.,3 Efficient electrochemical reduction of oxygen at the cathode of the FC requires stable and inexpensive catalysts ${ }^{2,4,5}$ and improved durability with high proton conductivity electrolyte membranes that perform well under hot and dry conditions. ${ }^{6-10}$

$\mathrm{NAFION}^{\mathrm{TM}}$ membranes with a hydrophobic tetra-fluoroethylene (PTFE) backbone and hydrophilic pendant chains terminating in sulfonate groups are still the most commercially used PEMs in the FC industry. ${ }^{11,12}$ The molecular structure of water confined inside the channels of NAFION ${ }^{\mathrm{TM}}$ membranes has been extensively studied at different hydration stages and is influenced by the size of water channels formed due to clustering of the hydrophilic sulfonic acid groups or by the closeness to the hydrophobic

\footnotetext{
${ }^{a}$ Methods for Material Development, Helmholtz-Zentrum für Materialien und Energie GmbH, 12489 Berlin, Germany. E-mail: ljiljana.puskar@helmholtz-berlin.de

${ }^{b}$ Humboldt-Universität zu Berlin, Experimentelle Biophysik, 10115 Berlin, Germany

${ }^{c} 3 M$ Energy Components Program, 3M Center, St Paul, MN 55144, USA

${ }^{d}$ Freie Universität Berlin, Fachbereich Physik, 14195 Berlin, Germany

${ }^{e}$ School of Chemistry, Monash University, Victoria, 3800, Australia
}

polymer backbone. ${ }^{12-15}$ Although very stable and efficient at proton transport at a high relative humidity $\left(0.1 \mathrm{~S} \mathrm{~cm}^{-1}, 100 \%\right.$ $\mathrm{RH}$ and $\left.30{ }^{\circ} \mathrm{C}\right),{ }^{16}$ its performance degrades at a lower humidity and under higher temperature conditions. ${ }^{17}$

The efficiency of the proton conductivity under dryer conditions of PEMs is largely influenced by the water retention capability. ${ }^{11}$ When abundant water molecules are present a bulk diffusion in the central region of water channels is reported as dominant, ${ }^{18}$ either by the Grotthus mechanism ${ }^{19}$ in which the proton is delivered from one water molecule to the next by a local molecular motion, or by the vehicle mechanism where hydrated hydronium ions move through the solvent. ${ }^{20}$ A surface diffusion mechanism where a proton hops between adjacent sulfonic acid sites via intermediate water molecules becomes more important with increased water confinement at low hydration levels. ${ }^{18,21}$ The contribution from all the proton conductivity mechanisms should be considered in PEMs. ${ }^{18,21-23}$ The hydrated hydronium ions are found in Zundel ${ }^{24} \mathrm{H}_{5} \mathrm{O}_{2}{ }^{+}$or Eigen ${ }^{25} \mathrm{H}_{9} \mathrm{O}_{4}{ }^{+}$cation forms, however since in PEMs excess protons are abundant due to the high acidity, higher order structures $\mathrm{H}_{2 n+1} \mathrm{O}_{n}{ }^{+}$have also been reported. ${ }^{26}$

Recent developments towards improved PEM performance reported use of multi acid side chains to retain high proton conductivity, stabilizing additives for improved chemical or polymer nanofibers for mechanical stability. ${ }^{8,10,27}$ Having multiple acidic sites per side chain lowers the ionomer equivalent weight (EW = grams of ionomer per mole of acid) without compromising the mechanical stability and allows for the formation of larger ionic channels which increases proton conductivity. ${ }^{28}$ 
A

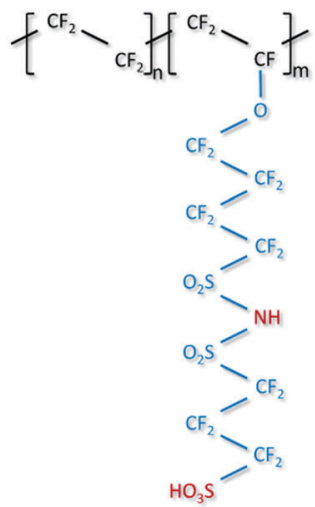

B

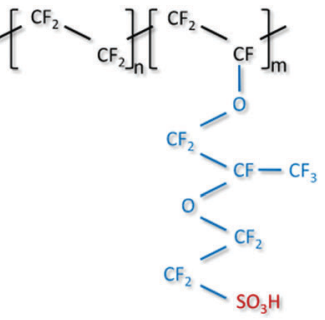

Scheme 1 Structure of 3M's PFIA (A) and Dupont NAFION ${ }^{\mathrm{TM}}$ membrane (B) ionomers.

Perfluoroimide acid or PFIA is one of these multi-acid PEMs recently developed by the 3M Company's (3M) Fuel Cell Components Group that incorporates a bis-sulfonyl imide group into pendant chains providing an additional source of the protonic group (Scheme 1A, compare Scheme $1 \mathrm{~B}$ for NAFION $^{\mathrm{TM}}$ ). ${ }^{8}$ Bis-sulfonyl imide is known to have an acid strength even higher than the terminal sulfonic acid in the gas phase. ${ }^{29}$ PFIA was reported by $3 \mathrm{M}$ as high performing with the low EW 625 but significant backbone crystallinity equivalent to ionomers of EW 1000. ${ }^{9}$ Fig. 1 shows the higher conductivity of PFIA in comparison to NAFION ${ }^{\mathrm{TM}}$ under different relative humidity conditions at $80{ }^{\circ} \mathrm{C}$.

Infrared spectroscopy as a technique sensitive to the molecular level changes in water, the functional ionic or acidic side groups as well as the backbone of materials has extensively been used to study PEM membranes. ${ }^{12,30-35}$ We applied Fourier transform infrared (FTIR) spectroscopy to follow the changes in $\mathrm{H}_{2} \mathrm{O}$ saturated PFIA membranes during heating to high temperatures under a range of humidity conditions. These in situ

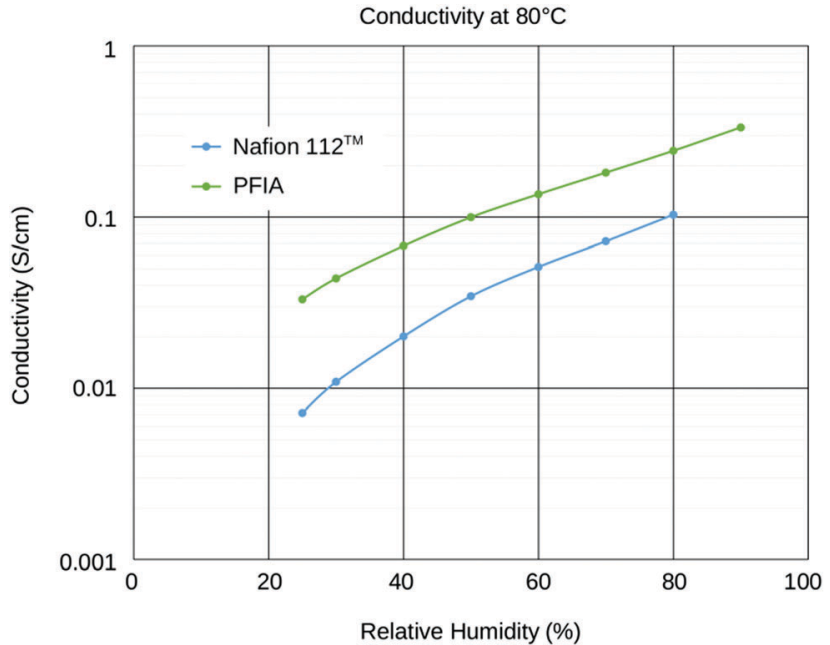

Fig. 1 Conductivity of $25 \mu \mathrm{m}$ thick $625 \mathrm{~g}$ per equivalent PFIA and $2100 \mathrm{~g}$ per equivalent $\mathrm{NAFION}{ }^{\mathrm{TM}}$ at $80{ }^{\circ} \mathrm{C}$ as a function of relative humidity. Conductivity was measured using a 4-point conductivity probe. measurements in conjunction with $2 \mathrm{D}$ correlation analysis allowed the full assignment of bands in the mid infrared region and further provided information on the microstructural changes occurring during heating and cooling processes. Comparison to the well-studied NAFION ${ }^{\mathrm{TM}}$ membrane provides a further understanding of the processes contributing to the proton conductivity at a low relative humidity.

\section{Experimental procedures}

\section{Materials}

PFIA membranes of $25 \mu \mathrm{m}$ thickness and $625 \mathrm{~g}$ per equivalent were obtained from the 3M's Fuel Cell Components Group. NAFION $^{\mathrm{TM}}$ NR211 membranes of $25 \mu \mathrm{m}$ thickness and $2100 \mathrm{~g}$ per equivalent were purchased from Ion Power $\mathrm{GmbH}$ in the acid $\left(\mathrm{H}^{+}\right)$form. Both membranes were cut into $\sim 2 \times 2 \mathrm{~cm}$ squares and then pre-treated to remove any impurities and fully convert to the $\mathrm{H}^{+}$form. The standard pre-treatment procedure ${ }^{36,37}$ involved lightly boiling the membranes $\left(\sim 80{ }^{\circ} \mathrm{C}\right)$ first in $3 \%$ $\mathrm{H}_{2} \mathrm{O}_{2}$ for one hour, two hours in deionized (DI) water followed by further one hour in $0.5 \mathrm{M} \mathrm{H}_{2} \mathrm{SO}_{4}$ and the final rinse with lightly boiling DI water. The membranes were rinsed after each of the boiling steps and stored in deionized water for at least 24 hours before the measurements. High purity alkali salts were obtained from Carl Roth $\mathrm{GmbH}$ ( $\mathrm{NaCl}$ 99.5\% and $\mathrm{KCl}$ 99\%). The PFIA and NAFION ${ }^{\text {TM }}$ NR211 membranes in the alkali salt-forms were prepared by soaking the pre-treated membranes in the corresponding 1.0 M alkali halide solutions for at least 24 hours at room temperature.

\section{Proton conductivity measurements}

PFIA membrane proton conductivity measurements were performed at 3M Company using an AC impedance method with a standard, in-plane, 4-point probe conductivity apparatus and platinum wire electrodes. ${ }^{38}$

Membrane samples of approximately $1 \mathrm{~cm}$ wide and $4 \mathrm{~cm}$ long were measured at $80{ }^{\circ} \mathrm{C}$ and at fixed humidity. The cell was connected to a potentiostat (Model 273, Princeton Applied Research) and an Impedance/Gain Phase Analyzer (SI 1260, Schlumberger). AC impedance measurements were performed using Zplot and Zview software (Scribner Associates). Temperature and relative humidity were controlled using a constant humidity oven (TestEquity Model 1000H). Between two and thirteen measurements were performed on each sample. The initial humidity was $70 \% \mathrm{RH}$ and data were collected at successive $10 \mathrm{RH}$ percentage point intervals upon lowering the RH to $20 \%$. Measurements were then taken as the humidity was increased from $20 \% \mathrm{RH}$ by increments of 10 percentage points up to $90 \% \mathrm{RH}$.

\section{FTIR measurements}

Temperature dependent mid-infrared spectra were measured in transmission mode using a Bruker Vertex 70/v instrument equipped with a $\mathrm{KBr}$ beam splitter, a DTGS detector and a globar as a radiation source. Pre-treated membranes with the 
excess surface water removed by Motic lens papers were placed between two $22 \mathrm{~mm}$ diameter and $2 \mathrm{~mm}$ thick ZnSe windows of a modified Harrick demountable FTIR transmission cell suitable for in-vacuum heating. A $630 \mu \mathrm{m}$ thick PTFE spacer was chosen to separate the windows and minimize the formation of fringes. Regions on opposing sides of the spacer were cut out to allow for gas purge through the gas/liquid inlet and outlet of the Harrick cell. Temperature was measured using two thermocouples positioned in the cuvette close to the sample. The temperature was recorded using a USB data logger (EL-USB-TC-LCD) with a time-resolution of 30 seconds. To control the temperature, a temperature controller (Harrick Model ATC-024-2) was modified to allow for fast heating to the desired temperature $\left(>200{ }^{\circ} \mathrm{C}\right)$. The sample was purged with air of defined humidity to control the dehydration/rehydration process. A relative humidity $(\mathrm{RH})$ of $80 \%$ was generated by purging dried air $(0.1 \% \mathrm{RH})$ through deionized water, whereas direct purging of dried air through the cell provided $0.1 \%$ RH. A $30 \% \mathrm{RH}$ in a non-flowing vapor environment was also employed to slow down the diffusion of water vapor to the sample and prolong the timescale of the rehydration process. Humidity of the cell was recorded throughout the experiment at an $\sim 30 \mathrm{~s}$ interval using two humidity sensors (Sensirion $^{\mathrm{TM}}$ EK-H4), placed at the inlet and the outlet of the cell. Time-dependent spectral datasets were recorded with a timeresolution of $1 \mathrm{~min}$ (co-adding 74 single scans) at $4 \mathrm{~cm}^{-1}$ spectral resolution. Spectra of the empty cell were used as a reference during the heating or cooling experiments. In addition, each of these measurement series was further referenced against the 'empty channel' spectra recorded when the translation stage containing the liquid cell was moved out of the line of the spectrometer thus accounting for variations in the spectrometer during the two sets of temperature measurements.

\section{Data treatment \& analysis}

Primary spectra recording, instrument and sample stage control, calculation of absorbance spectra and assembling datasets with the spectra as a function of time were done with the Bruker ${ }^{\mathrm{TM}}$ OPUS 7 spectroscopy software. All further data evaluation steps were performed with a home-made program for 'GNU Octave', a high-level programming language for numerical mathematics. ${ }^{39}$ The time-dependent spectral data were arranged column-wise in a matrix $M_{i, j}$ with $i=1 \ldots z, z$ being the number of the spectral interval and $j=1 \ldots T$ where $T$ is the total number of spectra obtained during the respective heating/cooling period. Consequently, the $j$ th column of $M$ describes the spectrum measured at the time $t=t_{0}+j \times \Delta t, t_{0}$ being the start time of the experiment and $\Delta t$ being the time-interval necessary for recording of one single spectrum.

For statistical analysis of the time/temperature-dependent datasets, a method based on singular value decomposition (SVD) and rotational analysis was used. ${ }^{40,41}$ Briefly, SVD was implemented to decompose the original spectral matrix $M$ into three matrices $U, S$ and $V$ where $M=U S V^{\mathrm{T}}$. $U$ is a $z \times z$ matrix of independent spectral components, $V$ is a $T \times T$ matrix of kinetics and $S$ is the $z \times T$ matrix, whose diagonal elements are the singular values and is zero otherwise.
The diagonal elements $S_{i}$ correspond to the significance of the associated spectral components $U_{i}$. Following SVD, a rotation procedure, ${ }^{40}$ based on the autocorrelation of the columns of $V$, was applied and the data matrix $M^{\prime}$ was reconstructed with a subset of the significant components, thereby discarding noise. This allowed for the estimation of the transition times and temperatures within the different steps involved, since it determines the main spectral components and their corresponding kinetics.

Further information on kinetics and the correlation of several bands was obtained from 2D correlation analysis. Another advantage of this method is that it allows for the estimation of the band order even when the precise normalization is not possible. A method based on the generalized 2D algorithm was used ${ }^{42,43}$ which provided the order of changes occurring in different bands as well as powerful deconvolution. Two contour maps are generated, synchronous and asynchronous, characterizing the kinetics of the sample.

Briefly, the dynamic spectrum of a system influenced by an external parameter change such as heating is given by: ${ }^{44}$

$$
\tilde{y}(\nu, t)= \begin{cases}y(\nu, t)-\bar{y}(\nu) & T_{\min }<t<T_{\max } \\ 0 & \text { otherwise }\end{cases}
$$

$\bar{y}(\nu)$ is a reference spectrum of the system, in our case it is the spectrum of the hydrated sample at room temperature. The cross correlation function allows comparison of the spectral changes $\tilde{y}(\nu, t)$ during the time of observation at two different wavelengths $\nu_{1}$ and $\nu_{2}$ :

$$
X\left(\nu_{1}, \nu_{2}\right)=\left\langle\tilde{y}\left(\nu_{1}, t\right) \times \tilde{y}\left(\nu_{2}, t^{\prime}\right)\right\rangle
$$

It can be written as a complex function with the real and the imaginary part corresponding to the synchronous and asynchronous correlation intensity, respectively:

$$
X\left(\nu_{1}, \nu_{2}\right)=\phi\left(\nu_{1}, \nu_{2}\right)+\mathrm{i} \Psi\left(\nu_{1}, \nu_{2}\right)
$$

The synchronous part of the correlation was then obtained numerically ${ }^{4,45}$

$$
\phi\left(\nu_{1}, \nu_{2}\right)=\frac{1}{T-1} \sum_{j=1}^{T} I_{j}\left(\nu_{1}\right) I_{j}\left(\nu_{2}\right)
$$

where $I_{j}\left(\nu_{i}\right)=I\left(\nu_{i}, t_{j}\right)$ is the absorbance at the given time/ wavenumber, and the asynchronous part of the correlation spectrum was determined using the Hilbert-Noda transformation matrix $N:^{44,45}$

$$
\Psi\left(\nu_{1}, \nu_{2}\right)=\frac{1}{T-1} y\left(\nu_{1}\right)^{T} N y\left(\nu_{2}\right)
$$

In the synchronous and asynchronous maps, yellow/red colors indicate positive intensities while cyan/blue regions indicate negative intensities. The synchronous map retains information on the direct, simultaneous correlation of bands. A positive cross-peak indicates the two related bands changing in the same direction whereas a negative one shows the opposite direction of change. This map is symmetric towards the line $\nu_{1}=\nu_{2}\left(I\left(\nu_{1}, \nu_{2}\right)=I\left(\nu_{2}, \nu_{1}\right)\right)$. The asynchronous correlation map, 
being antisymmetric with respect to $\nu_{1}=\nu_{2}\left(I\left(\nu_{1}, \nu_{2}\right)=-I\left(\nu_{2}, \nu_{1}\right)\right)$, provides information on the order in which the changes occur. The Noda rules ${ }^{43}$ are a convenient algorithm to estimate the temporal relationship between two bands: when the sign of the cross-peaks situated in the lower right is the same in the synchronous and asynchronous plots, the band with the lower wavelength undergoes changes prior to the band with the higher wavelength. Opposite signs indicate an inverted band order, whereas an intensity of zero in the asynchronous plot indicates that both bands change on exactly the same timescale. Sun et al. provided a simplified algorithm to determine the band order of two or more bands where only the signs of the synchronous and asynchronous cross-peaks are taken into account. ${ }^{46}$ For the present work, this method was used to calculate the band order when more than two bands were studied.

\section{Results and discussion}

Fig. 2 shows temperature dependent FTIR transmission spectra of a 25 micron water saturated PFIA film heated to $200{ }^{\circ} \mathrm{C}$ at the rate of approximately 9 degrees per minute under $80 \% \mathrm{RH}$. The portion of the spectra in the fingerprint region from 1500 to $500 \mathrm{~cm}^{-1}$ is shown in Fig. $2 \mathrm{~A}$ with the main absorbance peaks that undergo significant changes during the dehydration process indicated. The spectra of fully hydrated samples are shown in blue changing towards the dehydrated state represented by red colour. The strong and in this case saturating feature between 1275 and $1100 \mathrm{~cm}^{-1}$ is due to the asymmetric and symmetric $\mathrm{CF}$ stretching vibrations from $\mathrm{CF}_{2}$ units of the backbone, reported as not being substantially affected by the amount of water. ${ }^{31,32,47}$ The immediate decrease over the whole spectral range, particularly noticeable below $1000 \mathrm{~cm}^{-1}$, is caused by loss of "bulk water" or water clusters inside the channels of the fully hydrated PFIA. These features occur due to a combination of liberation modes found at $\sim 700 \mathrm{~cm}^{-1}$ in liquid water and the broad continuum water absorption stretching over the 3400 to $500 \mathrm{~cm}^{-1}$ region..$^{24,26,48}$

\section{Ionic forms}

The peak at $1056 \mathrm{~cm}^{-1}$ seen in the fully hydrated PFIA at room temperature decreases with temperature and dehydration, undergoes a blue shift to $1063 \mathrm{~cm}^{-1}$ and finally disappears, the effect also found in NAFION ${ }^{\mathrm{TM}}$ membranes heated to $200{ }^{\circ} \mathrm{C}$ (data not shown). For perfluorinated ionomers containing sulfonate groups, a band at $\sim 1060 \mathrm{~cm}^{-1}$ was assigned to the symmetric stretching vibration of dissociated $-\mathrm{SO}_{3}{ }^{-}$groups. ${ }^{23,31,49-52}$ In bis[(perfluoroalkyl)sulfonyl]imide, ionomers similar to NAFION ${ }^{\mathrm{TM}}$ membranes but with sulfonyl imide replacing the $-\mathrm{SO}_{3} \mathrm{H}$ acidic group, Byun et al. reported asymmetric SNS stretching vibration of ionic sulfonyl imide at $1069 \mathrm{~cm}^{-1} .{ }^{53}$ Similarly, a band at around $1056 \mathrm{~cm}^{-1}$ in $\left(\mathrm{CF}_{3} \mathrm{SO}_{2}\right)_{2} \mathrm{~N}^{-}$was assigned to the antisymmetric SNS stretch. ${ }^{54}$ Since both of these ionic groups are present in PFIA it is likely that symmetric stretch of $\mathrm{SO}_{3}{ }^{-}$ groups and the antisymmetric SNS stretch both contribute to the $1056 \mathrm{~cm}^{-1}$ band.
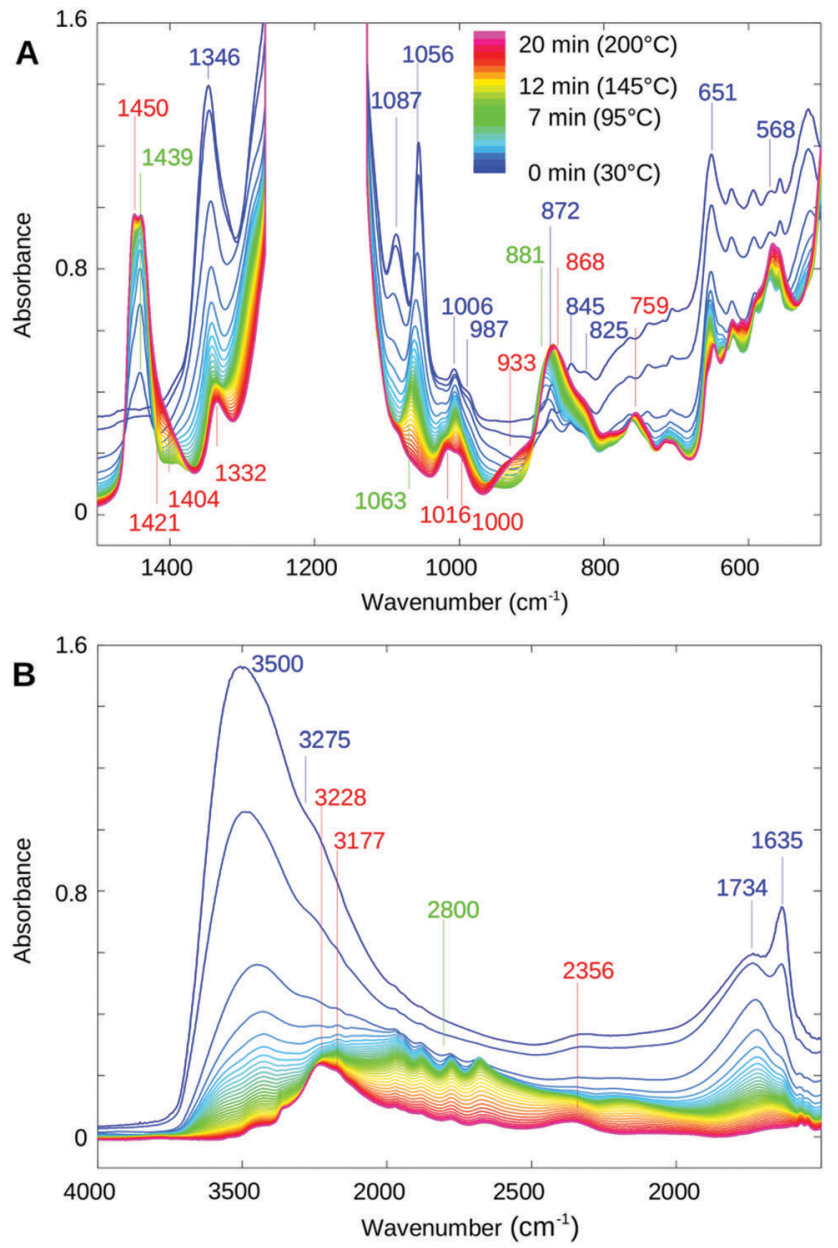

Fig. 2 Infrared spectra measured during the temperature-induced dehydration of PFIA, starting from the fully hydrated state at $30{ }^{\circ} \mathrm{C}, 80 \%$ relative humidity (blue) to the dehydrated state at $200{ }^{\circ} \mathrm{C}, 0.1 \%$ relative humidity (red). Spectra were measured with a time-resolution of $1 \mathrm{~min}$. (A) Spectral range between 1500 and $500 \mathrm{~cm}^{-1}$ dominated by fingerprint bands of PFIA. (B) Range between 4000 and $1500 \mathrm{~cm}^{-1}$ predominantly showing water bands.

Based on similarity to the NAFION ${ }^{\mathrm{TM}}$ films, a shoulder at $1285 \mathrm{~cm}^{-1}$ largely overlapped by the strong CF vibrations of the backbone can be attributed to the asymmetric stretching vibration of the $\mathrm{SO}_{3}{ }^{-}$ionic form. ${ }^{53,55,56}$ According to Rey et al. for the $\left(\mathrm{CF}_{3} \mathrm{SO}_{2}\right)_{2} \mathrm{~N}^{-}$system the symmetric SNS stretching absorption at $766 \mathrm{~cm}^{-1}$ is very weak, whereas the bending $\mathrm{SNS}^{-1} \mathrm{SO}_{2}$ appear stronger in the 655 and $605 \mathrm{~cm}^{-1}$ regions respectively. ${ }^{54}$ Based on the similarity to this work it is possible that the peak we observe at $651 \mathrm{~cm}^{-1}$ is due to the SNS bend of ionic sulfonyl imide. The strong absorbance peak at $1346 \mathrm{~cm}^{-1}$ in the hydrated PFIA film follows a similar behaviour to the $1056 \mathrm{~cm}^{-1}$ peak, however it is broader, red shifting and disappearing faster. In accordance with the literature on similar systems containing sulfonyl imide groups, this band can be assigned to the antisymmetric $\mathrm{SO}_{2}$ stretching mode of ionic sulfonyl imide, whereas the corresponding symmetric $\mathrm{SO}_{2}$ stretching mode is downshifted to $1087 \mathrm{~cm}^{-1}$ and also decreases on a fast time scale. ${ }^{53,54} \mathrm{~A}$ small band at $1332 \mathrm{~cm}^{-1}$ remaining in the dry film 
after 40 minutes at $200{ }^{\circ} \mathrm{C}$ does not appear sensitive to further dehydration. A peak at 1006 and a smaller shoulder at $987 \mathrm{~cm}^{-1}$ are both sensitive to dehydration. In a dry form the two peaks are of comparable intensities, appearing at 1016 and $1000 \mathrm{~cm}^{-1}$. In this region, the stretching modes of mixed CF and COC characters were reported in IR investigation of perfluoro ethers. ${ }^{57}$ In water saturated NAFION ${ }^{\mathrm{TM}}$ membranes a doublet at 981 and $969 \mathrm{~cm}^{-1}$ is assigned to the stretching vibrations of the COC linkages of the side chains, the former situated closer to the backbone and the latter to the $\mathrm{SO}_{3}{ }^{-}$terminal site and therefore more sensitive to the degree of hydration. ${ }^{31,58}$ In the case of PFIA only one COC linkage close to the backbone is present and not expected to be very sensitive to the water evaporation. Based on the literature and the similarity to our NAFION ${ }^{\mathrm{TM}}$ measurements we tentatively assign $987 \mathrm{~cm}^{-1}$ to the COC stretching.

\section{Acidic forms}

The bands appearing and increasing with the loss of water are correlated with the ionic $\mathrm{SO}_{3}{ }^{-}$and $\mathrm{SNS}^{-}$sites becoming neutralised. With the loss of water from NAFION ${ }^{\mathrm{TM}}$ membranes the formation of acidic $\mathrm{SO}_{3} \mathrm{H}$ was reported at $1415 \mathrm{~cm}^{-1}$ in agreement with our NAFION ${ }^{\mathrm{TM}}$ heating measurements. ${ }^{34,58}$ A similar feature at $1431 \mathrm{~cm}^{-1}$ in $\left(\mathrm{CF}_{3} \mathrm{SO}_{2}\right)_{2} \mathrm{NH}$ was attributed to the antisymmetric $\mathrm{S}=\mathrm{O}$ combined with $\mathrm{H}-\mathrm{NS}$ stretching vibration of the sulfonyl imide group. ${ }^{53,54}$

Based on the above literature findings and a close match in the position and band shape of the acidic $\mathrm{SO}_{3} \mathrm{H}$ band of our NAFION ${ }^{\mathrm{TM}}$ measurements to the shoulder peak at $\sim 1421 \mathrm{~cm}^{-1}$ in PFIA we tentatively assign the doublet peaks at 1450 and $1439 \mathrm{~cm}^{-1}$ to the antisymmetric $\mathrm{S}=\mathrm{O}$ of the acidic sulfonyl imide group and the band at $\sim 1421 \mathrm{~cm}^{-1}$ to the antisymmetric $\mathrm{S}=\mathrm{O}$ to the acidic $\mathrm{SO}_{3} \mathrm{H}$ form. Further analysis of these bands based on the dynamics study is presented later in the text. The symmetric $\mathrm{SO}_{2}$ vibration of the acidic sulfonyl imide is obstructed by the backbone absorption. ${ }^{54}$

In the region where three bands centred at 872, 845 and $825 \mathrm{~cm}^{-1}$ exist in the fully hydrated and also in $\mathrm{K}^{+}$or $\mathrm{Na}^{+}$ exchanged PFIA (data not shown), a broad feature appears and increases with the loss of water peaking at $868 \mathrm{~cm}^{-1}$ and at $825 \mathrm{~cm}^{-1}$ when in the fully dehydrated form. The shoulder at $825 \mathrm{~cm}^{-1}$ can be assigned to the symmetric stretching mode of the COC group of the neutralized form. ${ }^{34}$ Analogous to the $\left(\mathrm{CF}_{3} \mathrm{SO}_{2}\right)_{2} \mathrm{NH}$ molecule a $868 \mathrm{~cm}^{-1}$ band in PFIA can be assigned to the asymmetric stretch of the SNS bond. ${ }^{54}$ A small broad peak at $933 \mathrm{~cm}^{-1}$ in PFIA which appears at the later stage and together with the appearance of the shoulder at $1421 \mathrm{~cm}^{-1}$ is similar to the broad peak at $896 \mathrm{~cm}^{-1}$ in dehydrated NAFION ${ }^{\mathrm{TM}}$ membranes. Based on the similarity it can be ascribed to the $\mathrm{S}-\mathrm{O}$ vibration of acidic $-\mathrm{SO}_{3} \mathrm{H} .{ }^{23,59}$ A SNS bend in $\left(\mathrm{CF}_{3} \mathrm{SO}_{2}\right)_{2} \mathrm{NH}$ was reported at $647 \mathrm{~cm}^{-1}$ with a reasonable intensity, ${ }^{54}$ however we only observe a peak at $759 \mathrm{~cm}^{-1}$ increasing and blue shifting with a decrease of water. A similar peak in NAFION ${ }^{\mathrm{TM}}$ membranes is found at $810 \mathrm{~cm}^{-1}$ which suggests that it is related to the sulfonate part of the side chain or the backbone.

In the lowest part of the fingerprint region shown in Fig. 2A, from around 620 down to $500 \mathrm{~cm}^{-1}$ several peaks increase with the temperature, however only the $568 \mathrm{~cm}^{-1}$ band can be associated with the acidic forms of the functional groups (bands disappear upon $\mathrm{K}^{+}$or $\mathrm{Na}^{+}$ion exchange for hydrogen). A similar set of bands in NAFION ${ }^{\mathrm{TM}}$, however, shifted to slightly higher energies was assigned to the stretching and bending frequencies coming from $\mathrm{CF}_{2}$ molecules of the backbone. ${ }^{51}$

\section{Water region}

Fig. 2B shows the region from 5000 to $1500 \mathrm{~cm}^{-1}$ during the dehydration process. In the fully hydrated form (blue) it is dominated by the presence of water related absorbance bands with the prominent features at 3500 and $1635 \mathrm{~cm}^{-1}$ assigned to water stretching and water bending motions, both decreasing, particularly at the initial stages of dehydration. ${ }^{26,60,61}$ The upshift of the $\mathrm{OH}$ stretching mode with respect to bulk water reported at $3400 \mathrm{~cm}^{-1}$ indicates a less hydrogen-bonded environment within the confined water channels. ${ }^{56,60}$ The broadness of the band is due to the complicated mixture of overlapping contributions from the $\mathrm{HOH}$ bending overtone mixed with Fermi resonance of the stretching fundamental. ${ }^{60,61}$ In NAFION ${ }^{\mathrm{TM}}$, the tailing off at the lower wavenumber side was ascribed to the $\mathrm{OH}$ stretches arising from the solvated hydronium ions in configurations where they interact with acidic sulfonate groups. ${ }^{51,60}$

The $1635 \mathrm{~cm}^{-1} \mathrm{HOH}$ bending mode in hydrated ionomers is associated with the presence of larger water channels formed when enough water is present to connect the smaller hydrophilic domains of the side chains. In bulk water this band is centered at $1644 \mathrm{~cm}^{-1}$ which also points to a less intense hydrogen bonded environment within the hydrophilic water channels. ${ }^{62}$ A broad and slightly asymmetric band centered at $1734 \mathrm{~cm}^{-1}$, caused by hydrated hydronium ions in Zundel cation like conformations, ${ }^{26,63}$ decreases with dehydration. A similar band is observed in strong acids as part of a broad absorption continuum extending over the whole spectral region from the $\mathrm{OH}$ stretches down to below $1000 \mathrm{~cm}^{-1}$. $^{24}$ It is caused by a range of hydrogen bond lengths present in water where either $\mathrm{a} \mathrm{H}^{+}$ion exists in a delocalized form shared between two $\mathrm{H}_{2} \mathrm{O}$ molecules (Zundel cation$\left.\mathrm{H}_{5} \mathrm{O}_{2}{ }^{+}\right),{ }^{24}$ or a hydronium ion $\mathrm{H}$-bonded with three water molecules (Eigen cation- $\left.\mathrm{H}_{9} \mathrm{O}_{4}{ }^{+}\right){ }^{25}$ The continuum band is seen in the spectra of the hydrated samples (blue \& green) as absorption generally increased between 4000 and $1000 \mathrm{~cm}^{-1}$ with respect to the spectrum of the dried material (red). The initial decrease of the continuum band, as well as of the 3500 and $1635 \mathrm{~cm}^{-1}$ bands is attributed to the loss of bulk water as reported for NAFION ${ }^{\text {TM }} .^{26}$ During an intermediate state of the dehydration process (green lines) where the $\mathrm{OH}$ stretching and bending modes have largely lost their intensity a very broad band at around $\sim 2800 \mathrm{~cm}^{-1}$ is observed. A similar band seen in NAFION ${ }^{\mathrm{TM}}$, however much more pronounced, was assigned to the $\mathrm{OH}$ stretching mode of $\mathrm{H}_{3} \mathrm{O}^{+}$hydrogen bonded with $\mathrm{SO}_{3}{ }^{-}$and $\mathrm{CF}_{2}-\mathrm{O}-\mathrm{CF}_{2} \cdot{ }^{26} \mathrm{~A}$ band at $3228 \mathrm{~cm}^{-1}$ in dehydrated PFIA was assigned to the $\mathrm{NH}$ stretching frequency of the acidic form in similar systems containing a sulfonyl imide group. ${ }^{53,54}$

\section{Dynamics of the dehydration process}

Singular value decomposition revealed that the temperatureinduced dehydration occurs in three phases for all RH conditions 
studied (data not shown). The main spectral components showed that the phases are characterized by the same molecular events where only the kinetic constants differed, showing the fastest dehydration for the lowest RH as expected. Similar situation was observed for the rehydration process, however in the opposite direction. The initial phase (completed within approximately 8 minutes from the onset of heating for $80 \% \mathrm{RH}$, corresponding to 30 to $100{ }^{\circ} \mathrm{C}$ and within 1 minute for $0.1 \% \mathrm{RH}$, corresponding to 30 to $85{ }^{\circ} \mathrm{C}$ ) showed predominant disappearance of bulk water from the central part of the ionic channels (a band decrease at $3500,1635, \sim 700 \mathrm{~cm}^{-1}$ and the continuum) while other bands are largely unchanged. The second phase $(80 \% \mathrm{RH}$, $\sim 9-12 \mathrm{~min}=\sim 100-125^{\circ} \mathrm{C}$ ) is additionally characterized by a clear red shift of the $\mathrm{OH}$ stretching mode towards $3430 \mathrm{~cm}^{-1}$ corresponding to an increase of hydrogen bonding, and the appearance of a broader feature at around $2800 \mathrm{~cm}^{-1}$ resulting from the interaction of hydronium ions with the ionized functional groups, as reported to occur with the $\mathrm{SO}_{3}{ }^{-}$groups of NAFION ${ }^{\mathrm{TM}}{ }^{26}$ The broad band at $1734 \mathrm{~cm}^{-1}$ characteristic of $\mathrm{H}$-bonded hydronium ions loses intensity towards the later part of the dehydration phase and also shifts towards $1724 \mathrm{~cm}^{-1}$. Bands caused by the ionic forms of the functional groups (1056, 1087 and $1346 \mathrm{~cm}^{-1}$ ) show a particularly strong decrease in this second phase, whereas the corresponding acidic peaks $\left(1439 \mathrm{~cm}^{-1}\right.$, to a lesser extent $1450 \mathrm{~cm}^{-1}$ and $881 \mathrm{~cm}^{-1}$ ) increase, reflecting ongoing neutralization of the ionic groups. Further information on the order of infrared band changes can be obtained from 2D correlation spectra as described in the data treatment and analysis section. The $2 \mathrm{D}$ plots not only provide powerful deconvolution but also allow for a precise comparison of the kinetics, particularly when the normalization is difficult.

Fig. 3 shows the 2D correlation spectra of the second phase. A strong positive cross correlation in the synchronous map at $1054 \mathrm{~cm}^{-1}$ (band seen at $\sim 1056 \mathrm{~cm}^{-1}$ in the absorbance spectra of Fig. 2 and assigned to both $\mathrm{SO}_{3}{ }^{-}$and $\mathrm{SNS}^{-}$vibrations) with $1346 \mathrm{~cm}^{-1}$ and $1087 \mathrm{~cm}^{-1}$ shows that the band at $1054 \mathrm{~cm}^{-1}$ changes in the same direction as the bands corresponding to the $\mathrm{SO}_{2}$ vibrations of the ionic sulfonyl imide groups. In addition, a strong negative cross-peak of $1054 \mathrm{~cm}^{-1}$ with $1439 \mathrm{~cm}^{-1}$ and a shoulder at $1450 \mathrm{~cm}^{-1}$ agree with the increase of corresponding acidic bands. The absence of a positive or a negative cross-peak at $1054 \times 1439 \mathrm{~cm}^{-1}$ in the asynchronous map (Fig. 3B and for an enlarged view Fig. 3D) demonstrates that the intensity loss at $1054 \mathrm{~cm}^{-1}$ and the intensity gain at $1439 \mathrm{~cm}^{-1}$ follow the same time course whereas the appearance of the $1450 \mathrm{~cm}^{-1}$ shoulder is slightly delayed (negative asynchronous cross-peak). The bands at $1346 \mathrm{~cm}^{-1}$ (Fig. 3D) and $1086 \mathrm{~cm}^{-1}$ (Fig. 3C) also lose intensity at the same rate (zero cross-correlation in the asynchronous plot) as the $1054 \mathrm{~cm}^{-1}$ mode. The above findings and also the absence of any synchronous cross-correlation between $1054 \mathrm{~cm}^{-1}$ and the band near $1421 \mathrm{~cm}^{-1}$ (assigned to vibration of the acidic sulfonate groups) confirm that the decrease of the $\sim 1054 \mathrm{~cm}^{-1}$ band during this phase correlates with the formation of the acidic sulfonyl imide group and not with neutralization of the terminal $\mathrm{SO}_{3}{ }^{-}$. The strong correlation of the band at $1439 \mathrm{~cm}^{-1}$ with $1054 \mathrm{~cm}^{-1}$ is also in agreement
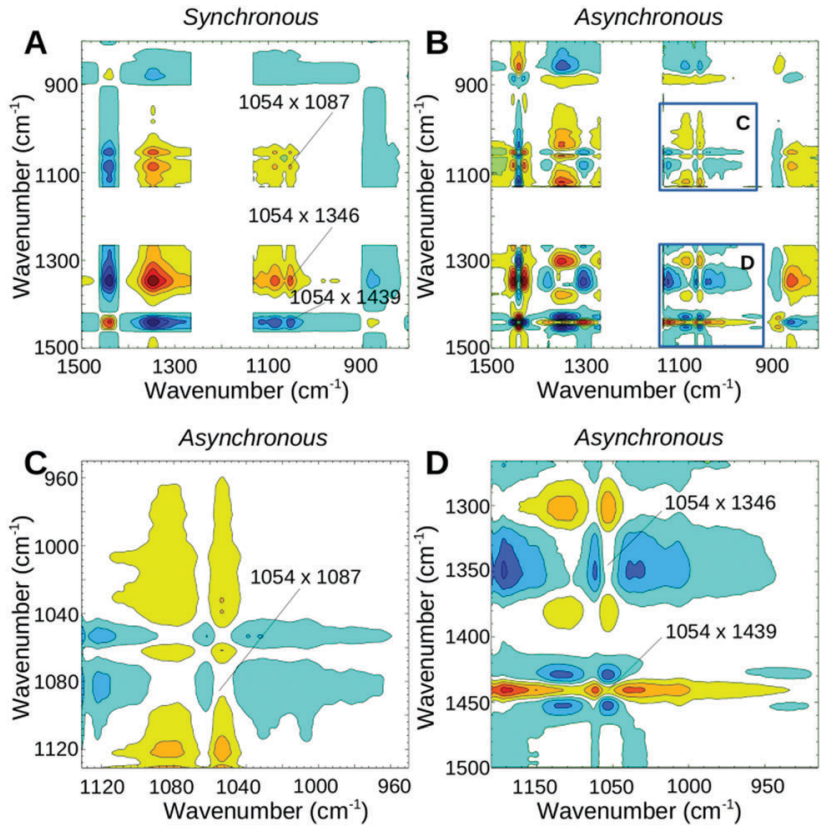

Fig. 3 2D correlation maps of the dehydration process of phase II, measured from $\sim 9$ to $\sim 12 \mathrm{~min}$ after start of the heating, primarily showing neutralization of the sulfonyl imide group. Yellow/red colours indicate positive peaks while cyan/blue colours represent negative peaks. (A) Synchronous map; (B) asynchronous map; ( $C$ and $D$ ) for clarity, two regions of the asynchronous map (as indicated in B) were enlarged.

with the earlier assignment of $1439 \mathrm{~cm}^{-1}$ to the antisymmetric $\mathrm{S}=\mathrm{O}$ stretch of the acidic sulfonyl imide group. ${ }^{54}$

The water molecules and hydrated hydronium ions that are still present in this phase (see blue/green spectra of the absorbance plot in Fig. 2) are expected to be involved in hydrogen bonded networks with the still ionized $\mathrm{SO}_{3}{ }^{-}$groups and/or the $\mathrm{S}=\mathrm{O}$ groups of the acidic bis(sulfonyl imide). Based on theoretical calculations, several configurations of hydrogen bonded structures were reported in ionomers having multiple acidic sites per side chains. ${ }^{27}$ For 3M PFIA the first proton dissociation was reported with only three water molecules in the lowest energy structure where the ionic sulfonate group is hydrogen bonded (via hydronium ion and two water molecules) to the $\mathrm{S}=\mathrm{O}$ group of the un-dissociated bis(sulfonyl imide group). Since hydrogen bonding causes a downshift of the corresponding $\mathrm{S}=\mathrm{O}$ stretching mode ${ }^{64}$ the strong $1439 \mathrm{~cm}^{-1}$ peak in this phase is most likely due to the $\mathrm{S}=\mathrm{O}$ mode hydrogen-bonded in a structure as reported by Clark et al., ${ }^{27}$ whereas the $1450 \mathrm{~cm}^{-1}$ shoulder is caused by a similar, but weakly or non-hydrogen bonded $\mathrm{S}=\mathrm{O}$ mode. By the end of this phase ( 12-15 min after start of heating), no further increase of the $1439 \mathrm{~cm}^{-1}$ band was observed while the bands at 1086 and $1346 \mathrm{~cm}^{-1}$ had (almost) completely disappeared, demonstrating that the majority of the SNS $^{-}$groups have already been neutralized.

The third measurement phase starting $\sim 13 \mathrm{~min}$ (corresponding to $150{ }^{\circ} \mathrm{C}$ ) after the onset of heating shows the final decrease of all water modes. The band in the region of $\mathrm{SO}_{3}{ }^{-}$ and SNS $^{-}$vibrations previously seen at $1054 \mathrm{~cm}^{-1}$ now appears at $1060 \mathrm{~cm}^{-1}$ still with a reasonable intensity. It undergoes a 

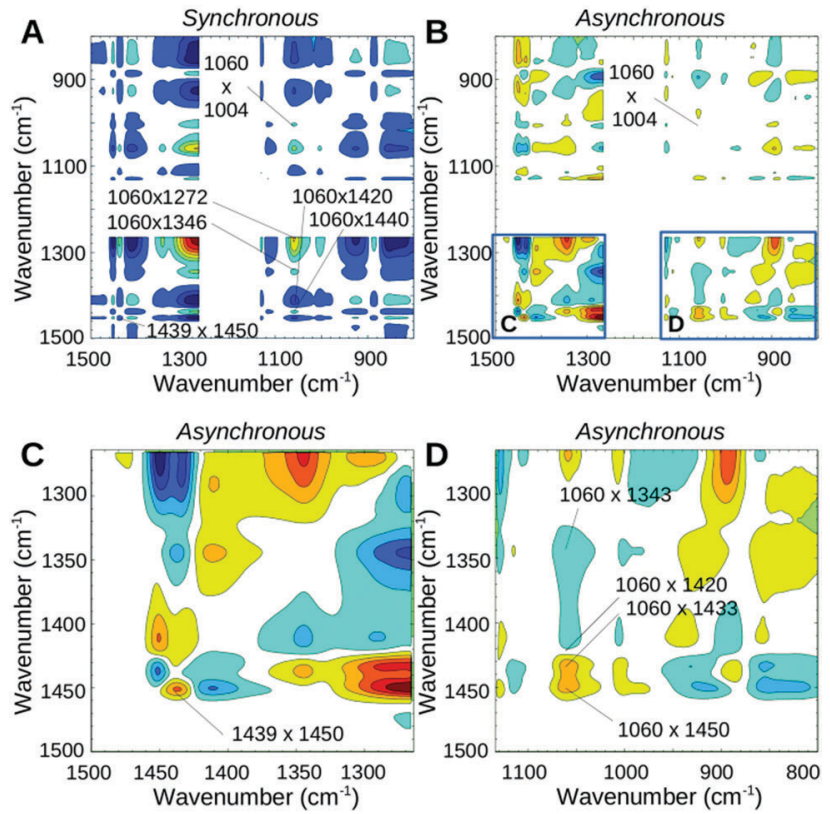

Fig. 4 2D correlation maps of phase III of the dehydration process, measured from $\sim 15$ to $\sim 25$ min after start of the heating. (A) Synchronous map; (B) asynchronous map; ( $C$ and $D)$ for clarity, two regions of the asynchronous map (as indicated in B) were enlarged.

further decrease until it completely vanishes when the sample is fully dehydrated. The synchronous map in Fig. $4 \mathrm{~A}$ reveals the strong correlation of $1060 \mathrm{~cm}^{-1}$ with an increase of the higher wavenumber portion of the doublet acidic peak at $1450 \mathrm{~cm}^{-1}$ and an increase of the broad shoulder peak at $\sim 1420 \mathrm{~cm}^{-1}$. Cross-peaks of $1060 \mathrm{~cm}^{-1}$ with $1343 \mathrm{~cm}^{-1}$ and $1086 \mathrm{~cm}^{-1}$ are not observed during this phase, suggesting that all the changes of $1060 \mathrm{~cm}^{-1}$ are now due to neutralization of the ionic $\mathrm{SO}_{3}{ }^{-}$ groups. The asynchronous plot (Fig. 4B and D) suggests that the higher wavenumber part of the acidic band at $1450 \mathrm{~cm}^{-1}$ occurring slightly faster than the $\mathrm{SO}_{3}{ }^{-}$band decreases $\left(1060 \mathrm{~cm}^{-1}\right)$ whereas the lower portion at $1439 \mathrm{~cm}^{-1}$ decreases at a similar (or slightly slower) timescale. Positive cross-peaks at 1439 and $1450 \mathrm{~cm}^{-1}$ in both synchronous and asynchronous plots confirm that the $1450 \mathrm{~cm}^{-1}$ band change is faster than the $1439 \mathrm{~cm}^{-1}$ change. It is likely that under high temperature conditions other intermediate structures are also present where water molecules or hydronium ions are hydrogen bonded either to the $\mathrm{SO}_{3}{ }^{-}$group prior to its neutralization, or to the $\mathrm{S}=\mathrm{O}$ groups of the bis-sulfonyl imide. ${ }^{27}$ However, since the minimum energy structure is reported for the connection of $\mathrm{SO}_{3}{ }^{-}$to the sulfonyl imide, the other intermediate structures are expected to disappear first. This effect may be responsible for the faster kinetics of the appearance of the $1450 \mathrm{~cm}^{-1}$ peak.

The data presented here support the following reaction model for the 3M PFIA during heat-induced dehydration:

Phase one. In this phase, predominantly water from the central part of the water-filled pores (bulk water) is removed.

Phase two. Ionic SNS ${ }^{-}$groups become protonated as seen by the initial decrease of the $1054 \mathrm{~cm}^{-1}$ band (the ionic form) and a corresponding increase in the $1450 / 1440 \mathrm{~cm}^{-1}$ region (the acidic form). The decrease of the bands at 1346 and $1086 \mathrm{~cm}^{-1}\left(\mathrm{SO}_{2}\right.$ vibrations of ionized $\mathrm{SNS}^{-}$) with the same kinetics supports the above. A hydrogen bonded network connects the ionic $\mathrm{SO}_{3}{ }^{-}$group with one of the oxygen atoms from the $\mathrm{S}=\mathrm{O}$ groups of the acidic sulfonyl imide, as reflected by the strong $1440 \mathrm{~cm}^{-1}$ band. Other, less abundant configurations where the oxygen is less hydrogen bonded are indicated by the up shifted shoulder at $1450 \mathrm{~cm}^{-1}$.

Phase three. The further loss of water now causes neutralization of the $\mathrm{SO}_{3}{ }^{-}$groups reflected by the further decrease of the $1060 \mathrm{~cm}^{-1}$ band and the appearance of the acidic form at $\sim 1421 \mathrm{~cm}^{-1}$ with the same kinetics. This process disrupts the hydrogen bonded network between the sulfonate and sulfonyl imide sites causing a $\sim 10 \mathrm{~cm}^{-1}$ blue shift of the antisymmetric $\mathrm{S}=\mathrm{O}$ vibrations of the acidic sulfonyl imide group from $\sim 1439$ to $1450 \mathrm{~cm}^{-1}$.

A summary of the band assignments for PFIA is given in Table 1.

Table 1 Infrared band positions of PFIA

\begin{tabular}{|c|c|c|}
\hline Band position $\left(\mathrm{cm}^{-1}\right)$ & Assignment & Literature $^{a}$ \\
\hline 3228 & NH str. of the HSNS group & 53 and 54 \\
\hline$\sim 2800$ & $\mathrm{OH}$ str. of $\mathrm{H}_{3} \mathrm{O}^{+}, \mathrm{H}$-bonded to $\mathrm{SO}_{3}{ }^{-}+\mathrm{CF}_{2}-\mathrm{O}-\mathrm{CF}_{2}$ & 26 \\
\hline$\sim 1635$ & Water $\mathrm{HOH}$ bend & 26,60 and 61 \\
\hline 1450 & Asym. $\mathrm{S}=\mathrm{O}$ of the HSNS group & 53 and 54 \\
\hline 1439 & Asym. $\mathrm{S}=\mathrm{O}$ of the HSNS group, $\mathrm{H}$-bonded & 53 and 54 \\
\hline 1285 & Asym. $\mathrm{SO}_{3}{ }^{-}$str. & 53,55 and 56 \\
\hline $1275-1100$ & Asym. and sym. $\mathrm{CF}$ str. from $\mathrm{CF}_{2}$ & 31,32 and 47 \\
\hline 1087 & Sym. $\mathrm{SO}_{2}$ str. of the SNS & 53 and 54 \\
\hline 1063 & Asym. SNS str. of the SNS ${ }^{-}$ & 53 and 54 \\
\hline 1054 & Sym. $\mathrm{SO}_{3}{ }^{-}$str. & 23,31 and $49-52$ \\
\hline 987 & Sym. COC str. & 23 and 58 \\
\hline 933 & $\mathrm{~S}-\mathrm{O}$ of the of the $\mathrm{SO}_{3} \mathrm{H}$ & 23 and 59 \\
\hline
\end{tabular}

${ }^{a}$ As used in the text, based on the experimental and theoretical works on similar systems. 


\section{Comparison to NAFION ${ }^{\mathrm{TM}}$ membranes}

For comparison studies, the dynamics of the rehydration process from hot and dehydrated PFIA and NAFION ${ }^{\mathrm{TM}}$ membrane samples were investigated. A non-flowing vapor environment of $30 \% \mathrm{RH}$ was used to ensure slow water uptake (low RH of the films in the initial stages of rehydration) and allow a more detailed kinetics study. Analogous to the dehydration, singular value decomposition (SVD) and rotational analysis identified several phases. For each of the phases, difference spectra were calculated by subtracting the first spectrum of a corresponding spectral dataset by all the subsequent spectra of the same dataset. This provided a better visibility of the humidity induced changes.

Fig. 5 shows the difference spectra of PFIA (left column) and NAFION $^{\mathrm{TM}}$ membranes (right column) for three time-windows. While during the first phase (A, B) the temperature was still decreasing, it stabilized at $35{ }^{\circ} \mathrm{C}$ prior to the second (C, D) and third phase (E, F). For both materials, the first phase shows water uptake under very low humidity conditions and the beginning of ionization of the sulfonate groups $\left(1060 \mathrm{~cm}^{-1}\right)$. Water molecules are incorporated into a very strong hydrogen bonded environment (or directly hydrogen bonded to the functional groups) as seen from the strong broad bands at $2600-2800 \mathrm{~cm}^{-1}$.
In the second phase both films continue with further water uptake under low humidity conditions. Within the early stage of this time window PFIA completes ionization of the sulfonate groups and begins some ionization of the sulfonyl imide groups, shown by the corresponding intensity changes of the 1450 and $1440 \mathrm{~cm}^{-1}$ bands (Fig. 5C) as described earlier in the text for the dehydration process. In NAFION ${ }^{\mathrm{TM}}$, however, all the acidic sites are completely ionized by the end of this phase, which is confirmed by the missing $\mathrm{SO}_{3}{ }^{-}$and $\mathrm{SO}_{3} \mathrm{H}$ bands in the difference spectra of the following phase. In PFIA during the second phase the $1630 \mathrm{~cm}^{-1}$ band appears as a clearly visible sharp band near the broad Zundel band at $1727 \mathrm{~cm}^{-1}$ indicating an increased contribution from the bending vibrations of bulk water molecules. ${ }^{26,32}$ Further support comes from the strong positive cross correlations of these two bands (Fig. 6A) in the synchronous $2 \mathrm{D}$ correlation spectra of PFIA. In addition, the asynchronous map (Fig. 6B) shows the formation of larger water clusters (1630 $\mathrm{cm}^{-1}$ band) developing faster than the changes in the $1730 \mathrm{~cm}^{-1}$ band. In contrast, NAFION ${ }^{\mathrm{TM}}$ only shows the broad $1723 \mathrm{~cm}^{-1}$ band under the same conditions (Fig. 5D). $1630 \mathrm{~cm}^{-1}$ was not resolved even with the $2 \mathrm{D}$ correlation maps (Fig. 6C and D) suggesting that no (or very few) larger water clusters

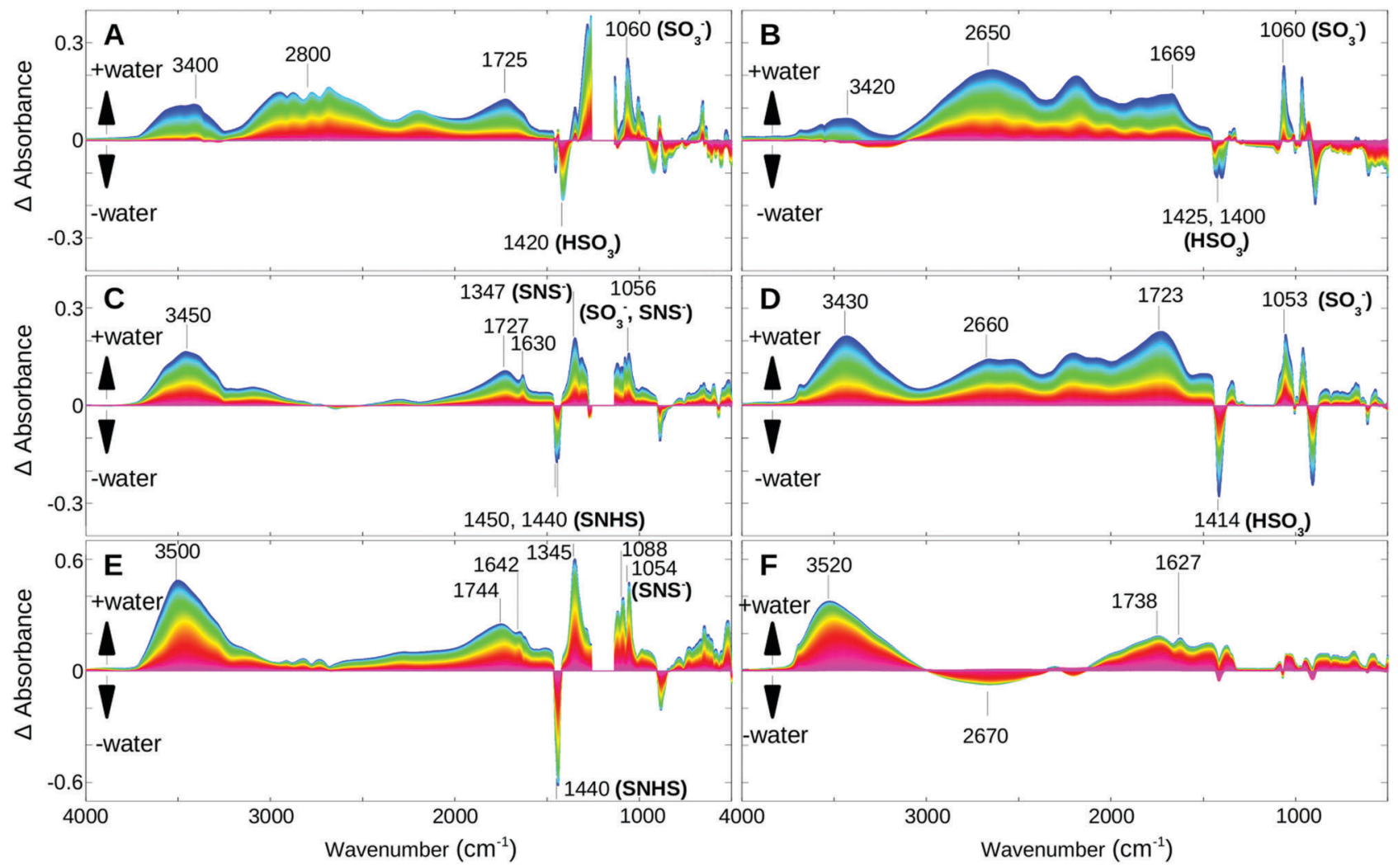

Fig. 5 Time-dependent difference spectra of rehydration of PFIA (left) and NAFION ${ }^{\mathrm{TM}}$ (right) at 30\% RH, measured during three different time windows. Difference spectra were calculated set-wise; the first spectrum of a given set is subtracted from each spectrum of that set. Negative bands correspond to bands of the less hydrated state, while positive bands correspond to bands that appear upon hydration. Red colors represent spectra measured early during the given time window, while blue colors correspond to spectra measured at a later stage. Marker bands of the sulfonate in its ionic or acidic forms $\left(\mathrm{SO}_{3}{ }^{-}, \mathrm{HSO}_{3}\right.$ ) and the sulfonyl imide (SNS ${ }^{-}, \mathrm{SNHS}$ ), the latter also including the $\mathrm{S}=\mathrm{O}$ modes of the SNS group, are indicated. (A) PFIA, 50-180 min; (B) NAFION ${ }^{\mathrm{TM}}, 50-180 \mathrm{~min}$; (C) PFIA, 180-270 min; (D) NAFION ${ }^{\mathrm{TM}}, 180-270 \mathrm{~min}$; (E) PFIA, 270-600 min; (F) NAFION ${ }^{\mathrm{TM}}, 270-600 \mathrm{~min}^{2}$ (A) and (B) Correspond to a temperature decrease from $\sim 80^{\circ} \mathrm{C}$ to $35^{\circ} \mathrm{C}$, while $(\mathrm{C}),(\mathrm{D}),(\mathrm{E})$ and $(\mathrm{F})$ were measured at a constant temperature of $35{ }^{\circ} \mathrm{C}$. 

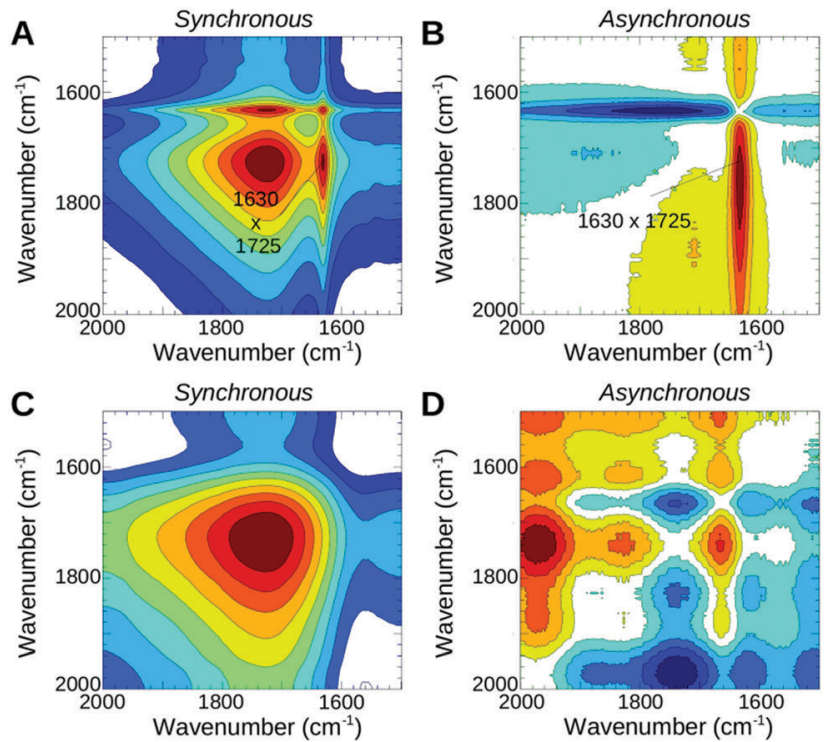

Fig. 6 2D correlation maps of the rehydration process of PFIA and NAFION $^{\mathrm{TM}}$, measured from $\sim 180$ to $\sim 270 \mathrm{~min}$ after the heater was switched off. (A and B) Synchronous and asynchronous maps of 3M PFIA; ( $C$ and $D$ ) synchronous and asynchronous maps of NAFION ${ }^{\mathrm{TM}}$. The maps show the correlation of the $\mathrm{HOH}$ bending mode at $1630 \mathrm{~cm}^{-1}$ with the $\mathrm{H}_{2} \mathrm{O}^{+}$mode at $1725 \mathrm{~cm}^{-1}$.

being present in this phase. Instead, a broad band at around $2660 \mathrm{~cm}^{-1}$ in NAFION ${ }^{\mathrm{TM}}$ shows the strong hydrogen bonding to the sulfonate groups.

In the third phase of rehydration (Fig. $5 \mathrm{E}$ and $\mathrm{F}$ ) where the films are now at a high humidity state, both films show a strong increase in the $\sim 3500$ and $\sim 1640 \mathrm{~cm}^{-1}$ bands. In PFIA further ionization of the sulfonyl imide groups, indicated by strong features at 1440 $(-), 1346(+), 1087(+), 1056 \mathrm{~cm}^{-1}(+)$ bands in the fingerprint region, offers additional protons for transport. In contrast, all the acidic sites have already been ionized in NAFION ${ }^{\mathrm{TM}}$, the broad band at around $2670 \mathrm{~cm}^{-1}$ vanishes to the benefit of a band at $3520 \mathrm{~cm}^{-1}$ with a clear isosbestic point at $3009 \mathrm{~cm}^{-1}$.

In NAFION ${ }^{\mathrm{TM}}$ more efficient proton conductivity at higher $\mathrm{RH}$ was associated with the existence of larger water clusters in the central region of the ion channels through which proton mobility is fast. ${ }^{18,31}$ However at lower humidity states, the slower surface mechanism becomes a predominant transport mechanism which is found to be considerably less efficient. ${ }^{18,21}$

Our rehydration data show that under low humidity conditions as seen during the 2nd phase, the water molecules incorporated into PFIA exist in a state more similar to bulk water than in NAFION $^{\mathrm{TM}}$ under similar conditions. The more efficient Grotthuss diffusion would be favored in PFIA, whereas in NAFION ${ }^{\mathrm{TM}}$ membranes under the low humidity conditions the proton transfer would be mostly via the surface diffusion mechanism.

\section{Conclusions}

FTIR spectroscopy was applied to study the temperature-induced dehydration and rehydration process of the perfluoroimide acid
(PFIA) ionomer having multiple acidic side groups. A comprehensive assignment of the bands in the mid-infrared spectra is presented. By means of statistical analysis and the $2 \mathrm{D}$ correlation method, the sequence of molecular events connected to the loss of water is deduced. A dehydration sequence model is proposed as follows: (i) loss of bulk water from the water channels, (ii) neutralization of the sulfonyl imide groups followed by (iii) neutralization of the terminal $\mathrm{SO}_{3}{ }^{-}$groups and formation of a hydrogen bonded network between sulfonic acid and the sulfonyl imide. A comparison with the well-studied NAFION ${ }^{\mathrm{TM}}$ membranes shows that under low humidity conditions PFIA is better at both water retention and water uptake. The existence of a "bulk-like" form of water in PFIA at low RH could account for better proton conductivity and a higher portion of a bulk diffusion. NAFION ${ }^{\mathrm{TM}}$ shows stronger $\mathrm{H}$ bonding with sulfonate groups at low $\mathrm{RH}$ thus having the higher portion of proton transport through the surface mechanism.

\section{Acknowledgements}

E. R. acknowledges support from the German Ministry of Education and Research (BMBF).

\section{Notes and references}

1 Z. Zuo, Y. Fu and A. Manthiram, Polymers, 2012, 4, 1627-1644.

2 M. K. Debe, Nature, 2012, 486, 43-51.

3 S. M. J. Zaidi, Polymer Membranes for Fuel Cells, Springer US, Boston, MA, 2009.

4 H. J. M. Hou, Materials, 2011, 4, 1693-1704.

5 R. K. Hocking, R. Brimblecombe, L.-Y. Chang, A. Singh, M. H. Cheah, C. Glover, W. H. Casey and L. Spiccia, Nat. Chem., 2011, 3, 461-466.

6 K. Sopian and W. R. Wan Daud, Renewable Energy, 2006, 31, 719-727.

7 O. Savadogo, J. Power Sources, 2004, 127, 135-161.

8 M. Schaberg, J. Abulu, G. Haugen, M. Emery, S. O’Conner, P. Xiong and S. Hamrock, ECS Trans., 2010, 33, 627-633.

9 C. Houchins, G. Kleen, J. Spendelow, J. Kopasz, D. Peterson, N. Garland, D. Ho, J. Marcinkoski, K. Martin, R. Tyler and D. Papageorgopoulos, Membranes, 2012, 2, 855-878.

10 S. Hamrock and K. E. Martin, DOE Hydrog. Progr., 2010, 748-753.

11 W. Grot, Chem. Ing. Tech., 1978, 50, 299-301.

12 K. A. Mauritz and R. B. Moore, Chem. Rev., 2004, 104, 4535-4585.

13 R. Hiesgen, S. Helmly, I. Galm, T. Morawietz, M. Handl and K. A. Friedrich, Membranes, 2012, 2, 783-803.

14 D. B. Spry, A. Goun, K. Glusac, D. E. Moilanen and M. D. Fayer, J. Am. Chem. Soc., 2007, 129, 8122-8130.

15 D. L. Wood, J. Chlistunoff, J. Majewski and R. L. Borup, J. Am. Chem. Soc., 2009, 131, 18096-18104.

16 S. Slade, S. A. Campbell, T. R. Ralph and F. C. Walsh, J. Electrochem. Soc., 2002, 149, A1556. 
17 L. Ghassemzadeh, M. Marrony, R. Barrera, K. D. Kreuer, J. Maier and K. Müller, J. Power Sources, 2009, 186, 334-338.

18 P. Choi, N. H. Jalani and R. Datta, J. Electrochem. Soc., 2005, 152, A1548.

19 C. J. T. de Grotthus, Ann. Chim., 1806, 58, 54-73.

20 N. W. DeLuca and Y. A. Elabd, J. Polym. Sci., Part B: Polym. Phys., 2006, 44, 2201-2225.

21 M. Phonyiem, S. Chaiwongwattana, C. Lao-ngam and K. Sagarik, Phys. Chem. Chem. Phys., 2011, 13, 10923-10939.

22 G. A. Ludueña, T. D. Kühne and D. Sebastiani, Chem. Mater., 2011, 23, 1424-1429.

23 P. C. Rieke and N. E. Vanderborgh, J. Membr. Sci., 1987, 32, 313-328.

24 G. Zundel, Advances in Chemical Physics, 2007, pp. 1-217.

25 M. Eigen, Angew. Chem., Int. Ed. Engl., 1964, 3, 1-19.

26 R. Buzzoni, S. Bordiga, G. Ricchiardi, G. Spoto and A. Zecchina, J. Phys. Chem., 1995, 99, 11937-11951.

27 J. K. Clark II, S. J. Paddison, J. K. Clark, S. J. Paddison, J. K. Clark II and S. J. Paddison, Electrochim. Acta, 2013, 101, 279-292.

28 S. J. Hamrock and M. A. Yandrasits, J. Macromol. Sci., Part C: Polym. Rev., 2006, 46, 219-244.

29 I. A. Koppei, R. W. Taft, A. S. Zbu, L. Hu, K. Sung, D. D. Desmarteau, L. M. Yagupolskii, Y. L. Yagupolskii, N. V Ignat, V. Kondratenko, Y. Volkonskii, V. M. Vlasov, R. Notario, P. Maria, I. A. Koppel, R. W. Taft, F. Anvia, S.-Z. Zhu, L. Hu, K. Sung, D. D. Desmarteau, L. M. Yagupolskii, Y. L. Yagupolskii, N. V. Ignat'ev, N. V. Kondratenko, A. Y. Volkonskii, V. M. Vlasov, R. Notario and P. Maria, J. Am. Chem. Soc., 1994, 116, 3047-3057.

30 D. T. Hallinan and Y. a Elabd, J. Phys. Chem. B, 2009, 113, 4257-4266.

31 K. Kunimatsu, B. Bae, K. Miyatake, H. Uchida and M. Watanabe, J. Phys. Chem. B, 2011, 115, 4315-4321.

32 M. Ludvigsson, J. Lindgren and J. Tegenfeldt, Electrochim. Acta, 2000, 45, 2267-2271.

33 S. Liu, A. J. a Aquino and C. Korzeniewski, Langmuir, 2013, 29, 13890-13897.

34 M. Danilczuk, L. Lin, S. Schlick, S. J. Hamrock and M. S. Schaberg, J. Power Sources, 2011, 196, 8216-8224.

35 D. T. Hallinan and Y. a Elabd, J. Phys. Chem. B, 2007, 111, 13221-13230.

36 T. A. T. Zawodzinski, M. Neeman, L. O. L. O. Sillerud and S. Gottesfeld, J. Phys. Chem., 1991, 95, 6040-6044.

37 T. A. Zawodzinski, T. E. Springer, J. Davey, R. Jestel, C. Lopez, J. Valeria and S. Gottesfeld, J. Am. Chem. Soc., 1993, 140, 5-9.

38 M. Emery, M. Frey, M. Guerra, G. Haugen, K. Hintzer, K. H. Lochhaas, P. Pham, D. Pierpont, M. Schaberg, A. Thaler, M. Yandrasits and S. Hamrock, ECS Trans., 2007, 11, 3-14.
39 J. W. Eaton, D. Bateman, S. Hauberg and R. Wehbring, GNU Octave version 4.0.0 manual: a high-level interactive language for numerical computations, 2015.

40 E. R. Henry and J. Hofrichter, Methods Enzymol., 1992, 210, 129-192.

41 M. Elgeti, E. Ritter and F. J. Bartl, Z. Phys. Chem., 2008, 222, 1117-1129.

42 I. Noda, J. Am. Chem. Soc., 1989, 111, 8116-8118.

43 I. Noda, Appl. Spectrosc., 1990, 44, 550-561.

44 I. Noda, in Handbook of Vibrational Spectroscopy, ed. P. R. Griffiths, John Wiley \& Sons, Ltd, Chichester, UK, 2006.

45 T. Pazderka and V. Kopecky Jr, Tech. Comput. Prague, 2008, 978-980.

46 S. Sun, H. Tang, P. Wu and X. Wan, Phys. Chem. Chem. Phys., 2009, 11, 9861.

47 Z. Liang, W. Chen, J. Liu, S. Wang, Z. Zhou, W. Li, G. Sun and Q. Xin, J. Membr. Sci., 2004, 233, 39-44.

48 H. R. Zelsmann, J. Mol. Struct., 1995, 350, 95-114.

49 C. Heitner-Wirguin, Polymer, 1979, 20, 371-374.

50 S. R. Lowry and K. A. Mauritz, J. Am. Chem. Soc., 1980, 102, 4665-4667.

51 J. Ostrowska and A. Narebska, Colloid Polym. Sci., 1983, 261, 93-98.

52 G. Xie, T. Okada and T. Arimura, Z. Phys. Chem., 1998, 205, 113-125.

53 C. K. Byun, I. Sharif, D. D. Desmarteau, S. E. Creager and C. Korzeniewski, J. Phys. Chem. B, 2009, 113, 6299-6304.

54 I. Rey, P. Johansson, J. Lindgren and J. C. Lasse, J. Phys. Chem. A, 1998, 102, 3249-3258.

55 A. Gruger, A. Régis, T. Schmatko and P. Colomban, Vib. Spectrosc., 2001, 26, 215-225.

56 M. Laporta, M. Pegoraro and L. Zanderighi, Phys. Chem. Chem. Phys., 1999, 1, 4619-4628.

57 J. Pacansky, M. Miller, W. Hatton, B. Liu and A. Scheiner, J. Am. Chem. Soc., 1991, 113, 329-343.

58 K. Feng, L. Hou, B. Tang and P. Wu, Phys. Chem. Chem. Phys., 2015, 17, 9106-9115.

59 D. S. Warren and A. J. McQuillan, J. Phys. Chem. B, 2008, 112, 10535-10543.

60 M. Falk, Can. J. Chem., 1980, 58, 1495-1501.

61 J.-B. Brubach, A. Mermet, A. Filabozzi, A. Gerschel and P. Roy, J. Chem. Phys., 2005, 122, 184509.

62 M. Falk, Spectrochim. Acta, Part A, 1984, 40, 43-48.

63 E. S. Stoyanov, I. V. Stoyanova and C. A. Reed, Chem. Sci., 2011, 2, 462-472.

64 D. Lin-Vien, N. B. Colthup, W. G. Fateley and J. G. Grasselli, The Handbook of Infrared and Raman Characteristic Frequencies of Organic Molecules, Elsevier, 1991. 